\title{
A JUSTIÇA QUE VEMOS, A JUSTIÇA QUE NOS OLHA: IMAGEM E CULTURA VISUAL EM DIDI-HUBERMAN E MITCHELL
}

Renato Duro Dias*

\section{Resumo}

O presente artigo discute imagem e cultura visual a partir de Georges Didi-Huberman (2010, 2013, 2020) e W.J.T. Mitchell $(2015,2017)$, tendo como referência algumas representações de justiça nas artes visuais. Desde o renascimento à contemporaneidade a justiça tem sido retratada sob as mais variadas formas estéticas. Neste estudo, de abordagem qualitativa, farse-á análise de algumas obras, procurando entender as relações entre imagem e justiça. Utiliza-se, portanto, do campo da cultura visual para pensar as representações imagéticas, com vistas à produção discursiva sobre a justiça e seus sistemas. Trata-se de pesquisa de cunho interdisciplinar que conecta a arte ao direito.

Palavras-chave: Arte; Cultura Visual; Direito; Imagem; Justiça.

\section{THE JUSTICE WE SEE, THE JUSTICE THAT LOOKS AT US: IMAGE AND VISUAL CULTURE IN DIDI-HUBERMAN AND MITCHELL}

\begin{abstract}
This article discusses image and visual culture from Georges Didi-Huberman (2010, 2013, 2020) and W.J.T. Mitchell (2015, 2017), having as reference some representations of justice in the visual arts. From the renaissance to the contemporary, justice has been portrayed in the most varied aesthetic forms. In this study, with a qualitative approach, some works will be analyzed, trying to understand how relations between image and justice. Therefore, we use the field of visual culture to think as imagery representations, with a view to discursive production on justice and its systems. It is an interdisciplinary research that connects art to law.
\end{abstract}

Keywords: Art; Visual Culture; Law; Image; Justice.

\section{Introdução}

Desde o renascimento a justiça tem sido retratada sob as mais variadas formas estéticas. Nos campos da História da Arte, Ciências Sociais e Humanidades estes estudos se tornam ainda mais potentes a partir da chamada virada imagética ou visual (MITCHELL, 2017). Para o direito e as teorias de justiça estes estudos começam a produzir sentido

\footnotetext{
* Vice-Reitor da Universidade Federal do Rio Grande - FURG. Professor da Faculdade de Direito e do Programa de Pós-Graduação em Direito - Mestrado em Direito e Justiça Social (FURG). Doutor em Educação (UFPel) com período na Universidade de Lisboa, Portugal. Vice-líder do Laboratório Imagens da Justiça - Grupo de Pesquisa (CNPq). Av. Itália, km 8, Campus Carreiros, Rio Grande, RS, Brasil.
} CEP: 96203-900. renatodurodias@gmail.com 
especialmente nas últimas décadas, quando se faz necessário compreender outras percepções sobre a justiça levando em conta esses regimes visuais.

Dentro desta perspectiva, a presente investigação pretende discutir imagem e cultura visual a partir de Georges Didi-Huberman (2010, 2013, 2020) e W.J.T. Mitchell (2015, 2017), tendo como elementos de referência algumas representações de justiça nas artes visuais extraídas de diversos estilos e períodos históricos.

Neste estudo, de abordagem qualitativa, far-se-á análise de algumas obras, procurando entender quais as relações entre imagem e justiça. Utiliza-se, portanto, do campo da cultura visual para pensar as representações imagéticas com vistas à produção discursiva sobre a justiça e seus sistemas.

Trata-se de pesquisa de cunho interdisciplinar que conecta a arte ao direito, ancorada em três (03) etapas. Primeiramente problematizam-se os conceitos de imagem, cultura visual e virada imagética com base nas discussões teóricas de Didi-Huberman e Mitchell, procurando decifrar o campo das visualidades.

Numa segunda etapa analisam-se as obras: Justice (1508-1511) de Rafael Sanzio, Allegory of Justice (1750-1775) de Gaetano Gandolfi, God, Law (1981), de Jean-Michel Basquiat e Justicia (1991) de León Ferrari, a fim de entender como em determinados momentos a justiça, a lei ou o direito são representados pictórica e escultoricamente.

Por fim, discutem-se como estas experiências visuais afetam a sociedade contemporânea e tem potencializado o sentido da visão em nosso cotidiano, agregando outros mecanismos de leitura sobre o mundo, a realidade que nos cerca e a justiça. Entende-se que estes elementos são capazes de aproximar arte, cultura visual e direito.

\section{Imagem e cultura visual em Didi-Huberman e Mitchell}


Pesquisadores e pesquisadoras com inspiração na "virada linguística" ${ }^{2}$ e na ideia de que nossas experiências de estar no mundo são filtradas por meio da linguagem, adotaram suas reflexões partindo das relações entre a presença ou ausência, bem como o significado das imagens para a construção entre sujeito e objeto. Estes estudos ganharam potência nos anos 1980-90, especialmente, nos Estados Unidos e Inglaterra, tendo como um de seus principais expoentes W.J.T. Mitchell (2015, 2017).

Este campo, também chamado de estudos visuais, institucionalizou-se nos Estados Unidos a partir dos anos 90, no final do século XX. Os dois programas de pesquisa de nível de pós-graduação que se constituíram de modo pioneiro nos Estados Unidos foram organizados pela colaboração interdepartamental. A primeira iniciativa se desenvolveu a partir de 1989 e originou o programa de Estudos Culturais e Visuais da Universidade de Rochester, que integrou profissionais da área da história da arte e da literatura comparada. Em seguida, em 1998, foi criado o programa de Estudos Visuais na Universidade de Califórnia de Irvine (UCI) por iniciativa dos programas de história da arte e de cinema. Neste quadro, destaca-se a importância da colaboração da história da arte para outras disciplinas. (KNAUSS, 2008, p. 154)

As interpretações estão alicerçadas em objetos visuais (alguns deles obras de arte) com a finalidade de "capturar", "compreender", "tocar" a imagem, dotando-as de significados. Estas análises procuram investigar as propriedades físicas das imagens, mas avançam sobre a função social que o produto imagético faz emergir. Entendendo, portanto, que a visão, operação física, e a visualidade, fato social, estão vinculadas a estas percepções de mundo. (JAY, 2003/2004, p. 15)

O ato de ver não é o ato de uma máquina de perceber o real enquanto composto de evidências tautológicas. $\mathrm{O}$ ato de dar ver não é o ato de dar evidências visíveis a par de olhos que se apoderam unilateralmente do "dom visual" para se satisfazer unilateralmente com ele. Dar a ver é sempre inquietar o ver, e seu ato, em seu sujeito, Ver é sempre uma operação de sujeito, portanto uma operação fendida, inquieta, agitada, aberta. Todo olho traz consigo sua névoa, além de informações de que poderia num certo momento julgar-se o detentor. (DIDI-HUBERMAN, 2010, p. 77)

Tanto para a História da Arte como para os Estudos Visuais, disciplinas que estudam a imagem, os termos 'pictórico', “visual' e 'icônico' referem-se a uma abordagem sobre artefatos visuais que reconhece essas demandas epistemológicas, em sua maioria de base interdisciplinar (MITCHELL, 2015, 2017). Neste sentido, parece prudente reforçar o leque de

\footnotetext{
2 A virada linguística ou giro linguístico é um movimento da filosofia contemporânea que aproximou epistemologicamente a filosofia com as estruturas da linguagem, possibilitando entender que toda a realidade por nós construída se constituiu a partir de nomes cujas características são próprias do campo da linguagem. Para mais detalhamento ver Rorty (1998).
} 
possíveis intersecções que estes estudos visuais comportam: desde relações com as Ciências Sociais, especialmente a Antropologia, passando pelas humanidades, como é o caso da História. Alguns autores como Meneses entendem que o campo da cultura visual estaria ligado diretamente aos estudos culturais.

\begin{abstract}
Na virada da década de 1980 dá-se não só a convergência de várias abordagens, interesses e disciplinas em torno do campo comum da visualidade, como também uma percepção cada vez mais ampliada, inclusive fora dos limites acadêmicos, da importância dominante da dimensão visual na contemporaneidade. A difusão da comunicação eletrônica e a popularização da imagem virtual obrigam à procura de novos parâmetros e instrumentos de análise, que articulam os esforços da Sociologia, Antropologia, Filosofia, Semiótica, Psicologia e Psicanálise, Comunicação, Cibernética, Ciências da Cognição. Campos que se estruturam como os estudos de comunicação de massa e, em particular, a moda assumida principalmente nos Estados Unidos e na Inglaterra pelos chamados "cultural studies". (MENESES, 2003, p. 23)
\end{abstract}

As investigações de Mitchell (2015, 2017), tiveram repercussões importantes para os estudos visuais, principalmente pela cunhagem do termo "virada pictórica" (MITCHELL, 2017) ou também denominada por Jay (2003) de "virada visual". Rejeitando análises reducionistas, como as semióticas, Mitchell argumenta que as imagens devem ser consideradas independentemente da linguagem, possibilitando que suas presenças ou ausências escapam a nossa habilidade linguística para descrever ou interpretar a imagem.

O que as imagens querem, portanto, não é serem interpretadas, decodificadas, adoradas, rompidas, expostas, ou desmistificadas, por seus expectadores, ou encantá-los. Elas podem nem mesmo desejar que comentadores bem-intencionados, que pensam que a humanidade é o maior elogio que se lhes pode oferecer, lhes outorgue subjetividade. Os desejos das imagens podem ser inumanos ou nãohumanos, mais bem modelados pelas figuras animais, máquinas, ciborgues, ou mesmo por imagens ainda mais básicas - aquilo que Erasmus Darwin chamava de “o amor das plantas". Portanto, o que as imagens querem, em última instância, é simplesmente serem perguntadas sobre o que querem, tendo em conta que a resposta pode muito bem ser "nada". (MITCHELL, 2015, p. 187)

Com estes argumentos Mitchell não nos coloca interditos para que interpretemos as imagens, antes pelo contrário, ele reforça que é no campo da ciência das imagens, da história da arte, que se dará "ênfase no campo social visual, nos processos cotidianos de olhar e ser olhado" (MITCHELL, 2015, p. 186). Para tal, é importante compreender as imagens como “individualidades complexas ocupando posições de sujeito e identidades múltiplas." (MITCHELL, 2015, p. 186). 
A imagem só existe para ser vista, por um espectador historicamente definido (isto é, que dispõe de certos dispositivos de imagens) e até as imagens mais automáticas, as das câmeras de vigilância, por exemplo, são produzidas de maneira deliberada, calculada para certos efeitos sociais. (AUMONT, 2012, p. 205)

A importância da "virada pictórica" ou "virada visual" reside, portanto, no fato de que as investigações de Mitchell, Jay e Didi-Huberman possibilitam a não restrição ao estudo de imagens àquelas tradicionalmente privilegiadas pela inclusão, o que estaria adstrito a categoria arte. Assim, os estudos visuais e a virada icônica, proposta pelo campo da cultura visual, permitem abordar não somente um único tipo de objeto visual, o artístico. Com este reconhecimento, as imagens fílmicas, vídeos, mídia (peças publicitárias, por exemplo), quadrinhos (HQs) entre outros podem ser contemplados como presentes neste campo de investigações.

a projeção do campo dos estudos visuais representam o reconhecimento de novas possibilidades de estudo da imagem e da arte, colocando a visualidade no centro de interrogação. Em seu desdobramento, o questionamento desenvolvido leva a repensar posturas diante de tradições disciplinares de investigação. (KNAUSS, 2008, p. 154).

Se esta empreitada acadêmica está concebida como estudos de diferentes objetos visuais, como a análise dos mecanismos humanos para os usos das imagens, ao invés de simplesmente a busca por palavras e/ou a construção de seus significados junto às imagens (MITCHELL, 2015), as maneiras pelas quais a percepção afeta a todos (independente do seu aspecto estético e poético), representa um importante desafio epistêmico no campo das visualidades (MITCHELL, 2015).

Por exemplo, não é inútil perguntar de que exatamente uma imagem é imagem, quais são os aspectos que aí se tornam visíveis, as evidências que apareceram, as representações que primeiro se impõem. Essa questão tem, ainda por cima, a vantagem de suscitar o interesse pelo como das imagens, outra questão crucial. (DIDI-HUBERMAN, 2015, p. 205)

Embora Didi-Huberman e Mitchell tenham delineado alguns dos paradigmas filosóficos, metodológicos e epistemológicos para pensar a imagem ${ }^{3}$, fica evidente que as possibilidades são tão infinitas quanto os próprios objetos. Esses novas abordagens propostas pelos estudos visuais (campo fértil da cultura visual), não tornam obsoletas outras possibilidades e formas estabelecidas de análise de imagens, antes pelo contrário, entende-se

\footnotetext{
${ }^{3}$ Nome da obra que dá suporte a um conjunto de estudos sobre imagem, resultado de um seminário realizado no Collége Internacional de Philosophie em 2007 e 2008, publicado no Brasil em 2015. (ALLOA, 2015, p. 16)
} 
que a "virada visual" ou "virada pictórica" possibilitam ampliar estes territórios, reafirmando que os artefatos visuais se recusam a ser confinados por interpretações binárias, fragmentadas ou encaixotadas. Desta forma, persistirá diferentes e novas narrativas capazes de pensar a imagem a partir do que vemos e do que nos olha (DIDI-HUBERMAN, 2010).

\section{Representações de justiça na cultura visual}

Os estudos visuais têm avançado gradualmente em diversos campos do conhecimento, possibilitando interfaces entre o direito, a arte, os estudos visuais e as concepções de justiça. Estas investigações procuram problematizar a centralidade da imagem como um dos elementos de discursividade para o campo jurídico, tendo como ponto de partida os estudos culturais.

Os usos das obras de artes, fotografias, filmes e peças publicitárias como documentos de análise estão consolidados nos campos das artes visuais, da sociologia e da antropologia. Dentro do direito, as pesquisas que envolvem estas metodologias e abordagens visuais ganham impacto e reflexão a partir dos estudos culturais. (SANTOS e DIAS, 2017, p. 46).

Embora recente no Brasil ${ }^{4}$, existe uma qualificada produção acadêmica que se traduz em algumas dissertações e teses, bem como publicações como são, por exemplo, as revistas Direito, Arte e Literatura ${ }^{5}$ (CONPEDI) e ANAMORPHOSIS - Revista Internacional de Direito e Literatura.

\footnotetext{
No próprio CONPEDI, Conselho Nacional de Pesquisa e Pós-graduação em Direito, a criação de um Grupo de Trabalho (GT) específico sobre Direito, Arte e Literatura irá se consolidar em 2009, no Encontro Nacional em Maringá, PR, quando por primeira vez a palavra "arte" é colocada no título do GT, então denominado "Direito, Arte, Literatura e Interdisciplinaridade". Embora seja importante salientar que, em edições anteriores, trabalhos científicos eram publicados e discutidos em outros espaços do mesmo CONPEDI. (SANTOS e DIAS, 2017, p. 46).
}

Além do mais, investigadoras e investigadores tem constituído Grupos de Pesquisa no $\mathrm{CNPq}$ com a mesma abordagem interdisciplinar utilizando os descritores arte, direito,

\footnotetext{
${ }^{4}$ Estas investigações aparecem com mais potência a partir de 2010.

5 A Revista Direito, Arte e Literatura do Conselho Nacional de Pesquisa e Pós-Graduação em Direito (CONPEDI) possui publicações desde 2015 e é fruto de produções acadêmicas originadas do GT de mesmo nome.
} 
imagem e justiça. Aqui alguns referenciados no Diretório dos Grupos de Pesquisa: Clínica de Direito e Arte (UFPR $)^{6}$, Arte e Direito (FDSM) ${ }^{7}$ e Laboratório Imagens da Justiça (UFPel) ${ }^{8}$.

Para tanto, seguindo os passos de algumas destas investigações, nesta etapa, analisam-se as obras: Justice (1508-1511) de Rafael Sanzio, Allegory of Justice (1750-1775) de Gaetano Gandolfi, God, Law (1981), de Jean-Michel Basquiat e Justicia (1991) de León Ferrari, a fim de entender como em determinados momentos a justiça, a lei ou o direito são representados pictórica e escultoricamente.

\subsection{Justice (1508-1511)}

Em Justice (1508-1511) de Rafael Sanzio, mulheres e anjos nos são apresentados sob uma aura de profundo equilíbrio em um cenário repleto de cores e adereços celestiais. A obra está localizada no teto cuja sala se denomina Stanza Della Segnatura, no Museu do Vaticano.

Figura 1 - Stanza Della Segnatura (1508-1511), Rafael Sanzio.

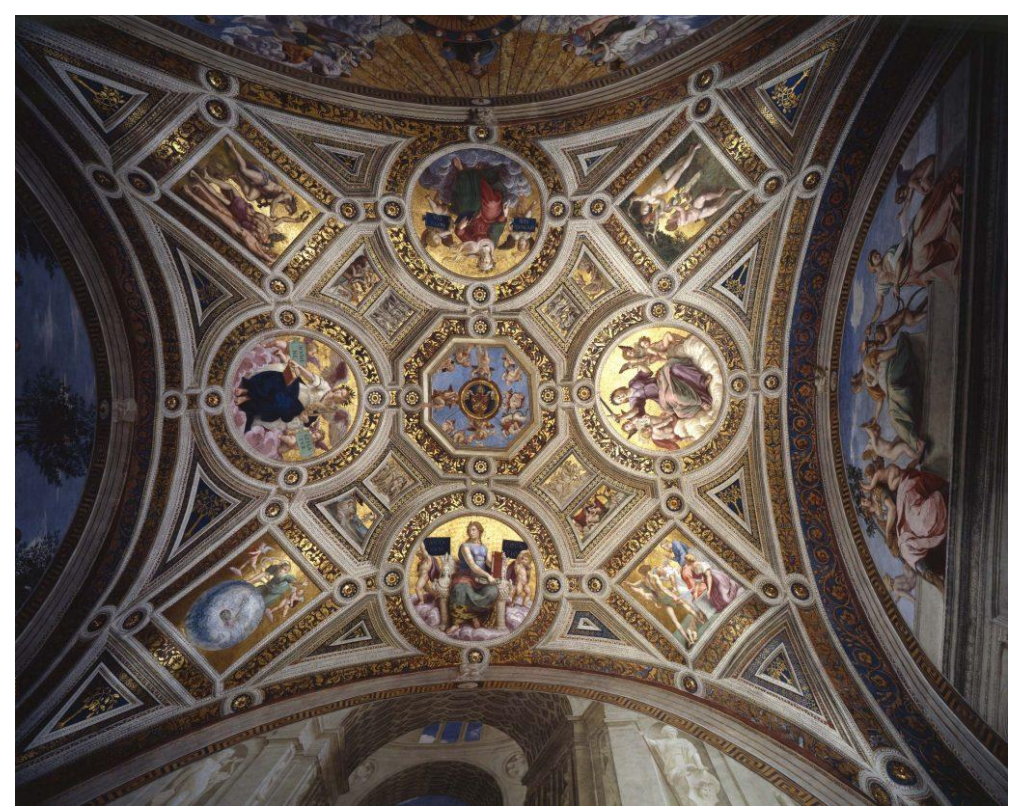

Fonte: Museu do Vaticano, 2021.

\footnotetext{
${ }^{6}$ De acordo com o Diretório dos Grupos de Pesquisa (CNPq), o grupo possui as seguintes linhas de pesquisa: a) Arte urbana e suas implicações jurídicas; b) Os limites da arte e c) a liberdade de expressão e Produção e mercado cultural.

${ }^{7}$ De acordo com o Diretório dos Grupos de Pesquisa (CNPq), o grupo possui as seguintes linhas de pesquisa: a) Efetividade dos direitos fundamentais sociais e b) Relações Sociais e Democracia.

${ }^{8}$ De acordo com o Diretório dos Grupos de Pesquisa (CNPq), o grupo possui as seguintes linhas de pesquisa: a) Arte e direitos humanos: gênero e sexualidades, acessibilidade e etnia e raça; b) Direito, Arte e Democracia e c) Justiça curricular; democracia; políticas curriculares e pedagogias.
} 
Trata-se de uma parte de um detalhe de afresco no teto, que contém muito menos ligações com os tempos clássicos e, segundo alguns estudiosos da obra de Rafael, recebeu poucos elogios relativamente às pinturas existentes nas paredes que o cercam. Nesta obra de Rafael, Teologia, Filosofia, Poesia e Justiça são representadas por mulheres sentadas como que pairando sobre nuvens. Essas quatro mulheres estão rodeadas por anjos, alguns deles com objetos em suas mãos.

No centro do teto verifica-se o ponto no qual Rafael pretende combinar as peças individuais, as representações da Teologia, Filosofia, Poesia e Justiça. As partes do teto foram escolhidas com um propósito deliberado, colocando Teologia e Filosofia, Poesia e Justiça em espaços diametralmente opostos. Ao que tudo indica, Rafael (1508-1511) buscava a atenção do espectador para o alto. Entre a Teologia e a Filosofia está muito contrastante, Rafael nos fornece dois caminhos separados a fim de encontrar a verdade: um por meio da fé (Teologia), o outro por meio da razão (Filosofia). Seguindo a mesma ideia de opostos se relacionando, a Poesia e a Justiça mostram como a disciplina e a inspiração se tornam um templo para a mente humana.

Figura 2 - Justice (1508-1511), Rafael Sanzio.

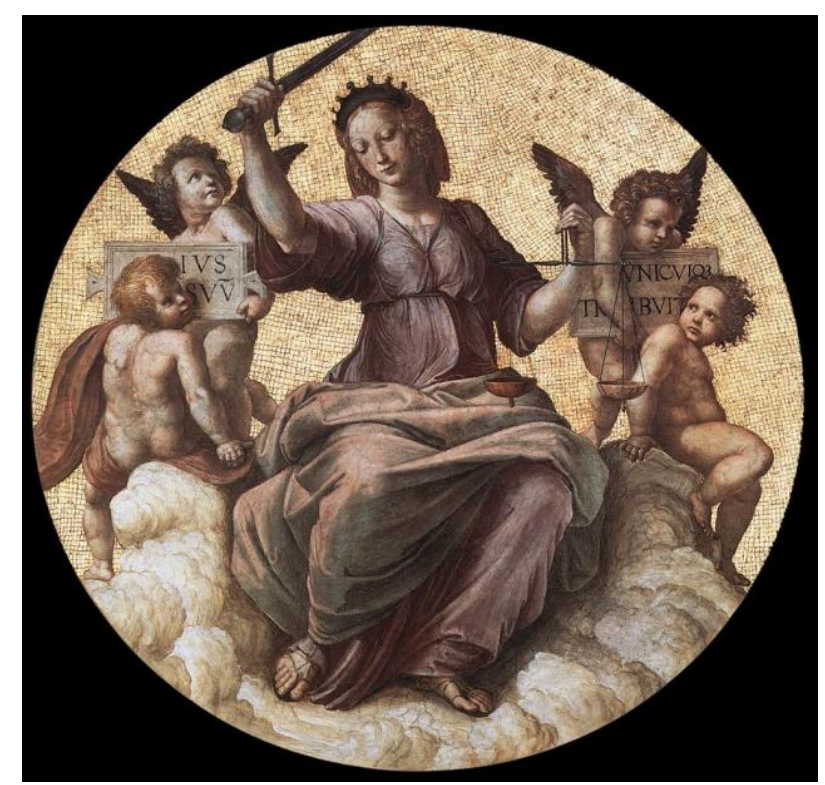

Fonte: Museu do Vaticano, 2021. 
Nesta obra de Rafael, a justiça a aparece sem venda empunhando na mão direita a espada, representativa da força, e na esquerda a balança, que indica o equilíbrio. É possível notar que a balança, imagem-símbolo, apresenta-se alinhada.

\begin{abstract}
Constituem-se em verdadeiros ícones representativos de justiça: balança, malhete (martelo) e deusa Themis (deusa da justiça). Essas representações semióticas populam o cotidiano daqueles que operam nos sistemas de justiça, de magistrados (judiciário) a advogados (OAB). Por outro lado, essas imagens também chamadas de tradicionais se avultam em sítios de internet, livros e agendas especializadas, lembranças e presentes e, sobretudo, na mídia televisiva (séries policiais, novelas, seriados de animação...). Portanto, pode-se dizer que essas imagens-símbolo constituem-se, numa primeira aproximação, ao campo especializado do conhecimento jurídico, ou seja, uma primeira percepção imagética de justiça. (DIAS, 2014, p. 191, grifei).
\end{abstract}

Justice ainda reproduz inscrições em duas placas. A primeira (à esquerda) com a inscrição Jus Suum e a outra (à direita) Unicuique Tribuere. Esta frase indica uma máxima latina "Dar a cada um aquilo a que tem direito" (EXPRESSÕES LATINAS, 2021). É importante descrever que embora sem venda, a mulher representada por Rafael está com o olhar para baixo, parecendo indicar o até reflexivo que se impõe a concepção tradicional de justiça. Uma imagem com características de uma justiça etérea.

\title{
3.2 Allegory of Justice (1750-1775)
}

No quadro Allegory of Justice (1750-1775), Gaetano Gandolfi utiliza-se de algumas referências da Escola Italiana que reforçam os elementos visuais da composição de Rafael e de tantos outros pintores de sua época. A obra exposta no Museu do Louvre em Paris retrata uma mulher empunhando em sua mão direita uma espada e na esquerda uma balança.

Figura 3 - Allegory of Justice (1750-1775), Gaetano Gandolfi. 


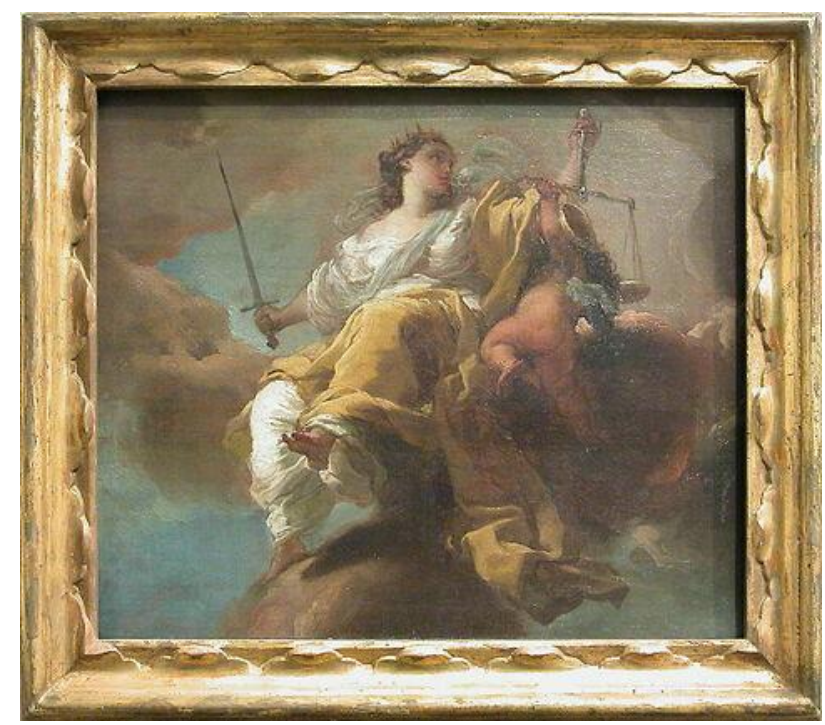

Fonte: Museu do Louvre, 2021.

Diferentemente da obra anterior, a espada aparece mais abaixo, enquanto que a balança não é representada com os pratos alinhados. Ao que indica, Gandolfi representa um anjo agarrado como se estivesse brincando com a balança, o que gera uma sensação estética distinta, típica do estilo barroco ao qual o pintor se vincula.

Gandolfi não parece fazer uma crítica à concepção de justiça apresentada pela obra de Rafael. Ele busca, com outras configurações, perspectiva cênica, cores e elementos reproduzir conceitualmente aquela iconologia de uma justiça celestial, em que figuram nuvens e anjos ao redor de uma identidade (entidade) feminina.

O olhar fugidio da representação de justiça em Allegory of Justice (1750-1775) de Gaetano Gandolfi, também é reflexo de um período característico das alegorias. Uma alegoria é uma representação concreta (por uma imagem, um símbolo ou um signo) de uma ideia abstrata de justiça. Aqui nesta alegoria de justiça, Gandolfi usa uma figura de linguagem representada por estes mesmos elementos de uma justiça divinal. Pode se dizer que não há, propriamente, uma ruptura com a significação com a iconografia proposta por Rafael, mas uma possibilidade de leitura recontextualizada e adequada ao estilo barroco.

\subsection{God, Law (1981)}


Ao contrário das obras anteriores, de Rafael e Gandolfi, se inscreve a produção artística de Jean-Michel Basquiat, artista contemporâneo americano que teve como marca a contestação.

Figura 4 - God, Law (1981), Jean-Michel Basquiat.

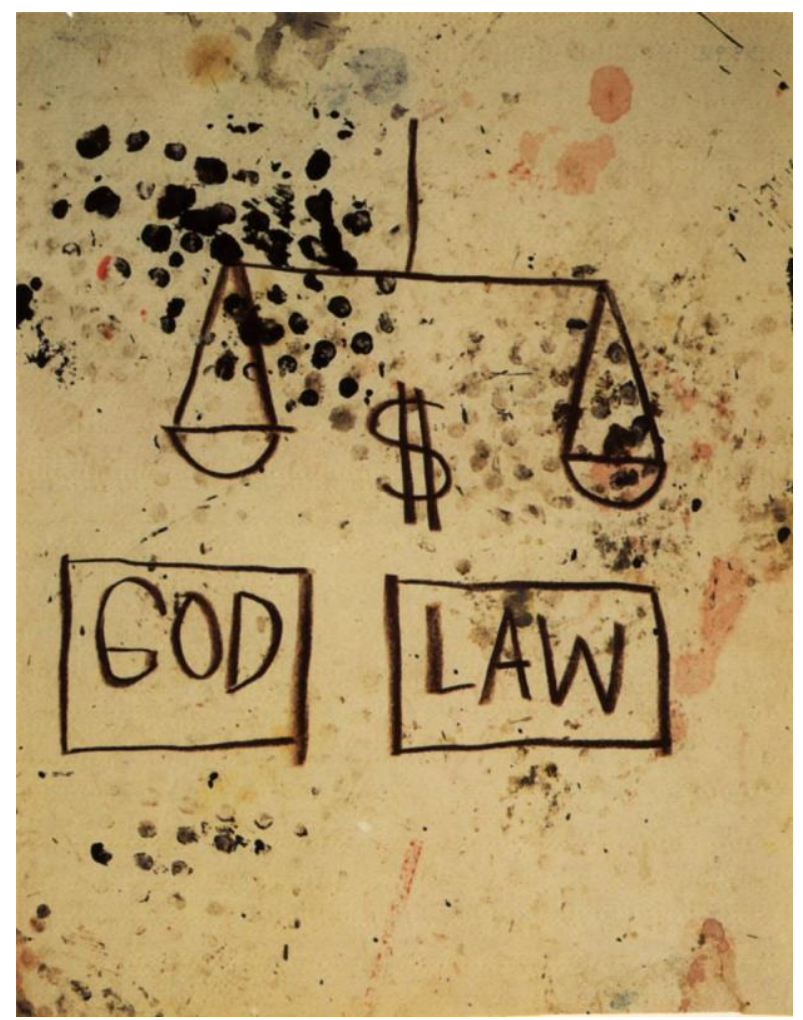

Fonte: Jean-Michel Basquiat Org, 2021.

Em God, Law (1981), Jean-Michel Basquiat reverbera sua imaginação para construir uma aproximação entre God (Deus) e Law (Lei, Direito), a partir de uma figura de balança levemente desalinhada, com um símbolo de cifrão entre seus pratos. A crítica é clara. Basquiat questiona a influência do dinheiro (poder do) ao aproximá-la de um dos ícones da representação da justiça, a balança.

Basquiat se revelou um grande artista ao escolher as ruas de Nova York para expressar a sua arte contemporânea. Destacado pelo seu toque inimitável, seja no grafite ou em serigrafias, Basquiat mescla de modo genial o traço às palavras. São frases e enumerações que representam parte daquilo que ele defendia: sua negritude, o som a partir da poesia e do hip hop. É na existência do homem afro-americano ameaçado pelo racismo, exclusão, 
opressão e capitalismo, que surge pelas mãos de Basquiat a tradicional marca contestatória. Não poderia ser diferente com God, Law (1981).

Em God, Law (1981) Basquiat problematiza justiça também sob a perspectiva racial, e aqui estamos falando da década de 1980, período que marca o fim do Panteras Negras, ação política militante que defendia os ideais de um "black power", movimento de resistência a opressão da população afrodescendente americana. O conceito de justiça na obra de Basquiat apresenta, também, uma crítica ao sistema de encarceramento, marcadamente racializado.

O regime das penas fixas foi adotado nos anos 80 em nível federal e em torno de um terço dos estados. Mas, à exceção de algumas raras jurisdições (sobretudo no Minnesota), as novas diretivas penais aumentaram as durações de detenção; elas tiveram impacto pequeno sobre as disparidades (sociais e raciais): favoreceram a superlotação das prisões e reduziram o papel dos juízes na fase de determinação das penas, aumentando o poder discricionário dos promotores. A rejeição do modelo da reabilitação contribuiu igualmente para transformar as prisões em entrepostos: se os programas de formação e de educação são perniciosos e fúteis, por que o Estado desperdiçaria seu dinheiro para financiá-los? (WACQUANT, 1999, p. 46).

Em última análise, em uma sociedade que exige direitos iguais para todos e todas, e, sobretudo, liberdade, autoridades encontram uma nova maneira de amalgamar entre criminosos as minorias negras. Basquiat se opõe a tudo isso, mesmo quando suas obras começam a ganhar espaços nas galerias de arte de Nova York. Neste contexto, a obra de Basquiat revela a potência de um jovem artista negro americano, que a partir da sua iconografia procurou romper com os paradigmas de uma sociedade violenta e opressora. A justiça de Basquiat, representada em God, Law (1981), ergue-se como uma denúncia a todo este sistema de desigualdade e impunidade

\subsection{Justicia (1991)}

Justicia (1991) do argentino León Ferrari é a última obra a ser analisada na presente investigação. Trata-se de uma escultura de arte contemporânea (KRAUS, 1984) exposta em algumas bienais, incluindo espaços expositivos no Brasil.

Nos últimos 10 anos coisas realmente surpreendentes têm recebido a denominação de escultura: corredores estreitos com monitores de TV ao fundo; grandes fotografias documentando caminhadas campestres; espelhos dispostos em ângulos inusitados em quartos comuns; linhas provisórias traçadas no deserto. Parece que nenhuma dessas tentativas, bastante heterogêneas, poderia reivindicar o direito de 
explicar a categoria escultura. Isto é, a não ser que o conceito dessa categoria possa se tornar infinitamente maleável. (KRAUSS, 1984, p. 87).

Figura 5 - Justicia (1991), León Ferrari.

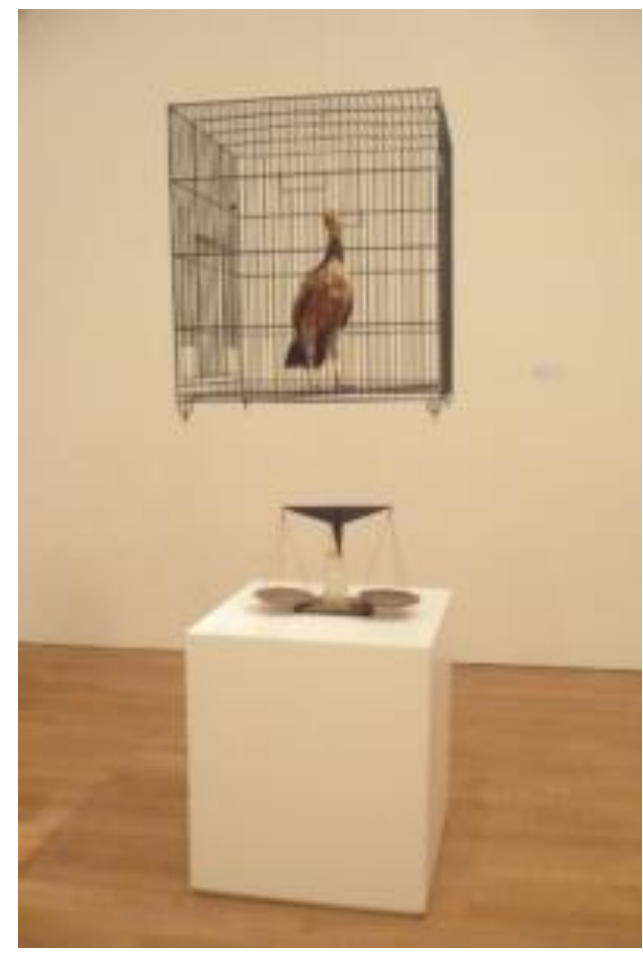

Fonte: LAART Galeria, 2021.

A obra de Ferrari é marcada por experimentações, que vão desde aquarelas a instalações. O artista contemporâneo argentino, que por alguns anos viveu em São Paulo, “incorpora textura e movimento em suas composições, por meio do uso de chapas de diversos tamanhos e diferentes metais [...] materiais não usuais, como garrafas, imagens recortadas, objetos de plástico, e chega a trabalhar com animais vivos". (ENCICLOPÉDIA ITAÚ CULTURAL, 2021).

É o caso de Justicia (1991), uma peça escultórica que se compõe de uma gaiola de arame contendo dentro uma ave viva ${ }^{9}$ e que está pendente, tendo abaixo um pedestal branco como base para uma balança em metal, cujos pratos estão alinhados. A proposta de Ferrari representa uma crítica aos sistemas de justiça, especialmente o argentino, já que a ideia de um animal vivo engaiolado poderia produzir alguns excrementos, que pela posição pendente

\footnotetext{
${ }^{9}$ Após alguns protestos de entidades ambientais, Ferrari substituiu o animal vivo por meio de taxidermia.
} 
poderiam cair sobre a balança metálica, maculando, assim, a imagem-símbolo. (DIAS, 2014, p. 191).

A obra de Ferrari está inserida no que se poderia denominar de arte politicamente engajada (ou artivismo), movimento visual que prima por demarcar ações culturais e de protesto, constituídos em diversos períodos da história.

\begin{abstract}
Artivismo é um neologismo conceptual ainda de instável consensualidade quer no campo das ciências sociais, quer no campo das artes. Apela a ligações, tão clássicas como prolixas e polémicas entre arte e política, e estimula os destinos potenciais da arte enquanto ato de resistência e subversão. Pode ser encontrado em intervenções sociais e políticas, produzidas por pessoas ou coletivos, através de estratégias poéticas e performativas [...] Artivismo consolida-se assim como causa e reivindicação social e simultaneamente como ruptura artística - nomeadamente, pela proposição de cenários, paisagens e ecologias alternativas de fruição, de participação e de criação artística. (RAPOSO, 2015, p. 5).
\end{abstract}

Em Justicia (1991) não é diferente, Ferrari nos traz elementos de desconforto e impacto visuais, produzindo uma sensação de estranhamento e ao mesmo tempo de reflexão, alterando uma pretensa visão etérea de justiça, tão bem representada pelas obras no período renascentista, para uma concepção crítica da justiça, em que a gaiola parece representar a grade do sistema punitivo penal.

Estas quatro (04) produções imagéticas destacadas, longe de serem as únicas no campo pictórico e escultórico, possibilitam experimentar esteticamente as visões de justiça, e permitem, ainda, avançarmos sobre a justiça que vemos e a justiça que nos olha.

\title{
4. A justiça que vemos, a justiça que nos olha
}

A experiência do visível é absolutamente dialética e inquietante (DIDIHUBERMAN, 2010). Nem sempre aquilo que vemos está absolutamente restrito a imagem, ou seja, nada além do que é visto. Nem sempre a imagem se inscreve a um circuito fechado que remete a si mesma (tautologia). É preciso buscar na imagem algo para além do que é visto, o vazio que ela representa, que nos inquieta. A partir desta ambivalência DidiHuberman (2010) pretende discutir os dilemas do visível. 
Em O que vemos, o que nos olha, Didi-Huberman (2010) produz uma fábula visual a partir do romance Ulisses de James Joyce (1914-1921). Utilizando a célebre frase da obra literária de Joyce "fechemos os olhos para ver", Didi-Huberman nos adverte "devemos fechar os olhos para ver quando o ato de ver nos remete, nos abre a um vazio que nos olha, nos concerne e, em certo sentido, nos constitui”. (DIDI-HUBERMAN, 2010, p. 31).

Essa ambiguidade assumida pela ação do ver a imagem, na medida em que olhamos para ela e que ela de alguma forma nos olha, produz a possibilidade de compreender o visível como um campo expandido, não compartimentado. Para além da crença, pois Didi-Huberman (2010) nos alerta que existe outra disposição de ver a imagem além do que realmente se vê, é importante compreender o vazio como uma potência, não um limite.

Ao olhar o mar e nele ver a mãe depois de morta, a personagem Dedalus de Ulysses faz emergir a perspectiva de que mesmo sem tocar a imagem ela se apresenta visível: ““inelutável modalidade do visível” - Stephen Dedalus acaba de ver com os seus olhos os olhos de sua própria mãe moribunda erguerem-se para ele, implorando alguma coisa”. (DIDIHUBERMAN, 2010, p. 31).

Compreender a imagem como um jogo aberto, permite explorar a inevitável capacidade da imagem de nos olhar. Permite explorar o entre. Desta forma, quando se está no campo da cultura visual, da ciência da imagem e da história da arte, os perímetros de leitura são tão amplos quanto às possibilidades de experimentação estética e iconológica que elas (imagens) nos remetem.

Para as demais áreas do conhecimento, especialmente a Sociologia, a Antropologia, a História e a Filosofia os usos e métodos de leitura de imagem têm sido elemento revigorante de ampliação dos campos, parametrizando um conjunto de possibilidades que escapam ao texto escrito. No mundo do direito, em que a linguagem escrita é a base, utilizar-se do texto imagético irrompe paradigmaticamente o contexto da produção do conhecimento (teoria), alargando ao ateórico.

Nas ciências humanas, o fato do conjunto das experiências concretas serem negadas no âmbito da abstração se configura como um problema que se mantêm. Nesse aspecto, ainda que nenhum conhecimento da realidade seja possível fora de uma prévia investigação de suas partes, isso não implica que tenham que ser estudadas primeiramente de forma isolada, como um processo de especialização. Por exemplo, 
quando os domínios da ciência, da arte, e da religião são isolados uns do outros, e estudados separadamente, acabam contribuindo para que a cultura seja vista e apreendida de maneira compartimentada. Dessa forma, as manifestações culturais são passíveis de serem tomadas como experiências pré-teóricas, sujeitas a várias operações de abstração, e formadas por diferentes pontos de vista teóricos. Entendemos que a própria maneira como o cientista aborda o objeto isoladamente faz com que o objeto/produto cultural se apresente como ateórico. (WELLER et al., 2002, p. 381).

No campo (BOURDIEU, 1983) do conhecimento jurídico as representações imagéticas possibilitam dar sentido entre a justiça que vemos e a justiça que nos olha, parafraseando Didi-Huberman (2010). Significa, portanto, postular que as obras que enxergamos tem uma composição plástica apreensível aos nossos olhares, podendo ser “tocadas" (alcançadas) dentro da representação cênica, mas permite, também, concebê-las dentro de um vazio, em que elas figuram como campo do sensível.

A justiça que vemos, a justiça que nos olha é presença e ausência. É, sobretudo, ambivalência. Nas representações visuais aqui analisadas nas obras Justice (1508-1511) de Rafael Sanzio, Allegory of Justice (1750-1775) de Gaetano Gandolfi, God, Law (1981), de Jean-Michel Basquiat e Justicia (1991) de León Ferrari, a ambiguidade deve ser a condição de acontecimento para o que vemos e o que nos olha.

Essa condição epistêmica produzida pelas infinitas possibilidades de lermos (vermos) as imagens que representam a justiça refere-se a esta dialética do visível (sensível). Seja como imagem-símbolo (DIAS, 2014), seja como poética transgressora, o impacto de olhar a obra reflete a potência do que nela também não está dito. Porque imagem é continente a ser explorado.

Enfim, partindo da pergunta de (MITCHELL, 2017) "O que querem as imagens?" Poderíamos dizer que, a partir de diversos estilos e momentos históricos, as produções imagéticas de justiça querem que "Abramos os olhos para experimentar o que não vemos, o que não mais veremos - ou melhor, para experimentar que o que não vemos com toda a evidência (a evidência visível) não obstante nos olha como uma obra (uma obra visual) de perda." (DIDI-HUBERMAN, 2010, p. 34). 


\section{Considerações finais}

Este estudo de abordagem qualitativa procurou discutir imagens representativas de justiça, problematizando-as a partir dos referenciais teóricos de Georges Didi-Huberman (2010, 2013, 2020) e W.J.T. Mitchell (2015, 2017). Num primeiro momento, apresentaram-se os limites conceituais para o campo das imagens e da cultura visual, entendendo-os como um contexto inspirador e dialógico para reflexionar para além da tradicional concepção sobre a história da arte.

Olhando para as obras Justice (1508-1511) de Rafael Sanzio, Allegory of Justice (1750-1775) de Gaetano Gandolfi, God, Law (1981), de Jean-Michel Basquiat e Justicia (1991) de León Ferrari, procurou-se descortinar como a justiça é retratada em diversos tempos e estilos artísticos. Através destas imagens compreende-se a centralidade dos temas que envolvem o direito e a lei, sobretudo, mirando a justiça como elemento divinal e intocável (inalcançável).

Contemporaneamente essa percepção icônica de justiça se transfigura em uma crítica feroz ao "retrato-representação" que a própria justiça (sistemas de) produz. Neste entre discursivo as imagens de justiça operam como elementos capazes de construir conhecimento e assumem seu importante papel de dialogar com a realidade social.

Insta mencionar que a fim de discutir a justiça que vemos, a justiça que nos olha utilizou-se da liturgia de uma experiência imagética que acessa as zonas limítrofes entre o visível e o vazio. Para tal, adotou-se a estratégia hubermasiana de reconhecer os regimes estéticos e políticos presentes nas imagens que habitam nosso cotidiano.

Como campo aberto que são as imagens representam uma vontade de potência (NIETZSCHE, 2008), transcendem gerações e instigam a nós humanos estarmos diante delas. Sagradas ou profanas, dizendo tudo ou não representando nada, entende-se que estes elementos imagéticos de justiça são capazes de produzir significância, e, sobretudo, de aproximar a arte e a cultura visual do direito. 


\section{Referências bibliográficas}

ALLOA, Emmanuel (Org.). Pensar a imagem. Belo Horizonte: Autêntica Editora, 2015.

ANAMORPHOSIS - Revista Internacional de Direito e Literatura. Disponível em: https://rdl.org.br/seer/index.php/anamps Acesso em: 27 mar. 2021.

AUGÉ, Marc; DIDI-HUBERMAN, Georges; ECO, Umberto. L' experiénce des images. Bry-sur-Marne, França: INA Editions, 2011.

AUMONT, Jacques. A imagem. Campinas, SP: Papirus Editora, 2012.

BASQUIAT, Jean-Michel. God, Law (1981). Disponível em: http://www.jean-michelbasquiat.org/god-law/ Acesso em: 23 mar. 2021.

BOURDIEU, Pierre. O campo científico. In: ORTIZ, Renato (Org.); FERNANDES, Florestan (Coord.). Pierre Bourdieu. São Paulo: Ática, 1983.

CONPEDI. Revista Direito, Arte e Literatura. Disponível em: https://indexlaw.org/index.php/revistadireitoarteliteratura Acesso em: 27 mar. 2021.

DIAS, Renato Duro. Relações de poder e controle no currículo do curso de direito da FURG. Tese de Doutorado. Programa de Pós-Graduação em Educação, Universidade Federal de Pelotas. Pelotas, UFPEL, 2014. Disponível em: http://repositorio.ufpel.edu.br:8080/bitstream/prefix/3348/1/DIAS\%2C\%20Renato\%20Duro.p df Acesso em 29 mar. 2021.

DIDI-HUBERMAN, Georges. O que vemos, o que nos olha. São Paulo: Editora 34, 2010.

DIDI-HUBERMAN, Georges. Diante da imagem. São Paulo: Editora 34, 2013.

DIDI-HUBERMAN, Georges. Devolver uma imagem. In: ALLOA, Emmanuel (Org.). Pensar a imagem. Belo Horizonte: Autêntica Editora, 2015.

DIDI-HUBERMAN, Georges. Imagens apesar de tudo. São Paulo: Editora 34, 2020. 
Faculdade de Direito do Sul de Minas (FDSM). Arte e Direito. Disponível: http://dgp.cnpq.br/dgp/espelhogrupo/634166 Acesso em: 27 mar. 2021.

ENCICLOPÉDIA ITAÚ CULTURAL. León Ferrari (1920-2013). Disponível em: http://enciclopedia.itaucultural.org.br/pessoa19872/leon-ferrari Acesso em: 30 mar. 2021.

FERRARI, León. Justicia (1991). Disponível em: https://laart.art.br/blog/leon-ferrari/ Acesso em: 23 mar. 2021.

FISCHER, Rosa Maria Bueno. Televisão \& Educação: fruir e pensar a TV. Belo Horizonte: Autêntica Editora, 2013.

GANDOLFI, Gaetano. Allegory of Justice (1750-1775). Museu do Louvre. Disponível em: https://collections.louvre.fr/ark:/53355/c1010063908 Acesso em: 23 mar. 2021.

JAY, Martin. Relativismo Cultural e a Virada Visual. Aletria: Revista de Estudos de Literatura, $\quad$ v. $10, \quad$ n.11, $\quad$ p. $14 \quad-\quad 28, \quad 2003 . \quad$ Disponível: http://www.periodicos.letras.ufmg.br/index.php/aletria/article/view/2232 Acesso 24 mar. 2021.

JOYCE, James. Ulysses (1914-1921). Disponível em; http://www.dominiopublico.gov.br/download/texto/pp000012.pdf Acesso em: 30 mar 2021.

KNAUSS, Paulo. Aproximações disciplinares: história, arte e imagem. Anos 90, Porto Alegre, v. $15, \quad$ n. 28, p.151-168, dez. 2008. Disponível em: https://seer.ufrgs.br/anos90/article/view/7964 Acesso 25 mar. 2021.

KRAUSS, Rosalind. A escultura no campo ampliado. Revista Gávea, n.1, revista do Curso de Especialização em História da Arte e Arquitetura no Brasil, da PUC-Rio, em 1984, p. 8793.

Disponível

em: https://monoskop.org/images/b/bc/Krauss Rosalind 19792008 A escultura no campo am pliado.pdf Acesso 25 mar. 2021.

MENESES, Ulpiano T. Bezerra de Fontes visuais, cultura visual, História visual. Balanço provisório, propostas cautelares. Revista Brasileira de História. São Paulo, v. 23, nº 45, pp. 
11-36,

2003.

Disponível

em:

https://www.scielo.br/j/rbh/a/JL4F7CRWKwXXgMWvNKDfCDc/?lang=pt\&format=pdf

Acesso em: 24 mar. 2021.

MITCHELL, W. J. T.. O que as imagens realmente querem? In: ALLOA, Emmanuel (Org.).

Pensar a imagem. Belo Horizonte: Autêntica Editora, 2015.

MITCHELL, W. J. T. ¿Qué quieren las imagénes? Uma crítica de la cultura visual. VitoriaGasteiz, Espanha: Sans Soleil Ediciones, 2017.

NIETZSCHE, Friedrich. A Vontade de Poder. Rio de Janeiro: Contraponto, 2008.

RANCIÈRE, Jacques. As imagens querem realmente viver? In: ALLOA, Emmanuel (Org.). Pensar a imagem. Belo Horizonte: Autêntica Editora, 2015.

RAPOSO, Paulo. "Artivismo": articulando dissidências, criando insurgências. Cadernos de Arte e Antropologia, Salvador, Vol. 4, $\mathrm{n}^{\circ}$ 2/2015, pag. 3-12. Disponível em: https://journals.openedition.org/cadernosaa/909 Acesso 24 mar. 2021.

RORTY, Richard. The linguistic turn: essays in philosophical method. Cambridge: Cambridge University Press, 1998.

SANTIAGO JÚNIOR, Francisco das Chagas Fernandes. A virada e a imagem: história teórica do pictorial/iconic/visual turn e suas implicações para as humanidades. Anais do Museu Paulista. vol.27 São Paulo 2019 Epub 29 abr. 2019. Disponível em: https://www.scielo.br/j/anaismp/a/gXrx9PJsXNWwpQthp5HNckn/?lang=pt\# Acesso em: 25 mar. 2021.

SANTOS, Herson Alex; DIAS, Renato Duro. Possíveis intersecções entre criminologia cultural e artes visuais. Revista de Direito, Arte e Literatura e-ISSN: 2525-9911| Brasília |

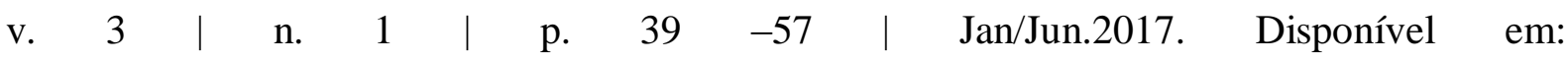
https://indexlaw.org/index.php/revistadireitoarteliteratura/article/view/2189 Acesso em: 24 mar. 2021. 
SANZIO, Rafael. Justice (1508-1511). Museu do Vaticano. Stanza delaa Segnatu Zra (Gratiae et Justitiae). Disponível em: https://m.museivaticani.va/content/museivaticanimobile/en/collezioni/musei/stanze-di-raffaello/stanza-della-segnatura/stanza-dellasegnatura.html\# Acesso em: 23 mar. 2021.

Universidade Federal de Pelotas (UFPel). Laboratório Imagens da Justiça. Disponível em: http://dgp.cnpq.br/dgp/espelhogrupo/520058 Acesso em: 27 mar. 2021.

Universidade Federal de Pelotas (UFPel). Laboratório Imagens da Justiça. Disponível em: https://wp.ufpel.edu.br/laboratorioimagensjustica/ Acesso em: 27 mar. 2021.

Universidade Federal do Paraná (UFPR). Clinica Direito e Arte. Disponível em: http://dgp.cnpq.br/dgp/espelhogrupo/292404 Acesso em: 27 mar. 2021.

WACQUANT, Loïc. Crime e castigo nos Estados Unidos: de Nixon a Clinton. Revista de Sociologia e Política, Curitiba, 13, p. 39-50, nov. 1999.

WELLER, Wivian; SANTOS, Gislene, SILVEIRA, Rogério Leandro Lima; ALVES, Adilson Francelino; KALSING, Vera Simone Schaefer. Karl Mannheim e o método documentário de interpretação: uma forma de análise das visões de mundo. Sociedade e Estado, Brasília, v. 17, n. 2, $\quad$ p. 375-396, jul./dez. 2002. Disponível: https://www.scielo.br/j/se/a/qnmsHCfCxdRTmcyJkGyR5YC/abstract/?lang=pt Acesso em: 30 mar. 2021. 